\title{
THE RELATIONSHIP BETWEEN DIETARY PATTERN AND SODIUM AND POTASSIUM LEVEL IN ADULT URINE
}

\author{
Reviana Christijani, Amalia Safitri, Dwi Anggraeni \\ Functional Implementing Innovation Unit of Stunting Prevention, \\ Agency of Health Research and Development, Bogor, West Java
}

\begin{abstract}
Background: Diets that contain sodium and potassium are important minerals that work as electrolytes that regulate the body's fluid balance. One of the mechanisms for balancing electrolyte levels is carried out by the kidneys. The kidneys will excrete excess sodium and potassium into the urine. This study aimed to examine the relationship between diet and the content of sodium and potassium in adult urine.

Subjects and Method: This was a cross-sectional study conducted in Bogor, West Java in 2016. A sample of 200 adults (100 males and 100 females) was selected for this study. The dependent variable was the sodium and potassium in urine. The independent variable was dietary pattern. The 24-hour urine sample was collected twice on non-consecutive days. The food consumption interview was conducted by 1x24-hour recall for twice on nonconsecutive days. The data were analyzed by Spearman Rank correlation.

Results: Potassium intake was positively correlated with potassium levels in 24-hour urine on the first $(r=0.20)$ and the second $(r=0.24)$ day of observation, and it was statistically significant $(\mathrm{p}=0.050)$ both in the male and female groups. Sodium intake was positively correlated with sodium levels in 24-hour urine both on the first $(\mathrm{r}=0.29)$ and second $(r=0.09)$ of observation, but it was statistically non-significant ( $p>0.050)$ both in the male and female groups.

Conclusion: Amount of potassium intake is directly proportional to the level of potassium content in adult urine.
\end{abstract}

Keywords: food patterns, diet, potassium, sodium, urine, adult

\section{Correspondence:}

Reviana Christijani. Functional Implementing Innovation Unit of Stunting Prevention, Agency of Health Research and Development. Jl. Dr. Sumeru 63 Bogor. Email: revianadamanik@gmail.com. Mobile: +62 8128519616.

The $8^{\text {th }}$ International Conference on Public Health Solo, Indonesia, November 17-18, 2021 | 238 https://doi.org/10.26911/AB.Medicine.ICPH.08.2021.41 